\title{
Host-Dependent Requirement for the Potato leafroll virus 17-kDa Protein in Virus Movement
}

\author{
Lawrence Lee, ${ }^{1}$ Peter Palukaitis, ${ }^{2}$ and Stewart M. Gray ${ }^{1}$ \\ ${ }^{1}$ United States Department of Agriculture-Agricultural Research Service, and the Department of Plant Pathology, Cornell \\ University, Ithaca, NY 14850; ²Scottish Crop Research Institute, Invergowrie, Dundee DD2 5DA, U.K.
}

Submitted 4 March 2002. Accepted 21 June 2002.

\begin{abstract}
The requirement for the $17-\mathrm{kDa}$ protein (P17) of Potato leafroll virus (PLRV) in virus movement was investigated in four plant species: potato (Solanum tuberosum), Physalis floridana, Nicotiana benthamiana, and $N$. clevelandii. Two PLRV P17 mutants were characterized, one that does not translate the P17 and another that expresses a P17 missing the first four amino acids. The P17 mutants were able to replicate and accumulate in agroinoculated leaves of potato and $P$. floridana, but they were unable to move into vascular tissues and initiate a systemic infection in these plants. In contrast, the P17 mutants were able to spread systemically from inoculated leaves in both Nicotiana spp., although the efficiency of infection was reduced relative to wild-type PLRV. Examination of virus distribution in $N$. benthamiana plants using tissue immunoblotting techniques revealed that the wild-type PLRV and P17 mutants followed a similar movement pathway out of the inoculated leaves. Virus first moved upward to the apical tissues and then downward. The P17 mutants, however, infected fewer phloem-associated cells, were slower than wild-type PLRV in moving out of the inoculated tissue and into apical tissues, and were unable to infect any mature leaves present on the plant at the time of inoculation.
\end{abstract}

Additional keywords: agroinoculation, Luteoviridae, movement protein, Polerovirus, tissue immunoblot analysis.

Plant viruses utilize the plant's own endogenous trafficking pathway in order to infect and spread within their hosts. Plasmodesmata, the plasma membrane channels that span the cell wall between all developing plant cells and most mature cells, play a role in the transfer of small molecules, such as ions and metabolites, as well as in the selective transport of macromolecules. Plant viruses are known to move through the plasmodesmata of several distinct cell and tissue boundaries using several distinct mechanisms (Carrington et al. 1996; Gilbertson and Lucas 1996; Lazarowitz and Beachy 1999; Lucas and Gilbertson 1994; Nelson and van Bel 1998; Séron and Haenni 1996). Infection by most plant viruses requires replication in the initially infected cells and then movement to adjacent cells through intercellular plasmodesmatal connections. This cell-to-cell movement requires viral-encoded

Corresponding author: S. M. Gray; Fax: +1-607- 255-2459; E-mail: smg3@cornell.edu

This article is in the public domain and not copyrightable. It may be freely reprinted with customary crediting of the source. The American Phytopathological Society, 2002. movement proteins that target the plasmodesmata and modify the size exclusion limit of the plasmodesmata. To move long distances, viruses must transverse bundle sheath cells, then move through specialized plasmodesmata that connect companion cells and sieve elements. These plasmodesmata have been identified as potential barriers to virus entry into the phloem even when normal cell-to-cell movement occurs (Ding et al. 1998). Furthermore, to establish a systemic infection, virus in the phloem elements must exit the vasculature and reestablish an infection in immature cells of young tissues. Interestingly, there is a greater abundance of plasmodesmata between sieve elements and other cell types in these immature tissues (Ding et al. 1996). Although virus movement proteins are involved in virus movement into and out of vascular tissues, other unidentified factors, both viral and host-dependent, appear to be required (Lucas and Wolf 1999; Nelson and van Bel 1998; Oparka and Turgeon 1999; Santa Cruz 1999; Thompson and Schulz 1999).

Potato leafroll virus (PLRV; genus Polerovirus, family Luteoviridae) can be introduced directly into vascular tissues by its aphid vectors (Mayo and Ziegler-Graff 1996). However, the movement of PLRV is phloem restricted. The virus moves in and out of sieve elements and between phloem-associated cells, but it is unable to move efficiently into and between infected mesophyll cells (Barker 1987; Nurkiyanova et al. 2000). It is unknown if PLRV requires a viral-encoded protein or proteins to mediate movement into phloem tissues and, if so, if the movement protein is not functional in other tissues. Co-infection of PLRV with Potato virus Y (PVY) does lead to an increase in the number of mesophyll cells infected with PLRV, but the virus still is unable to move efficiently between infected mesophyll cells (Barker 1989). Presumably, PVY cellto-cell movement or host defense suppression machinery can assist the movement of PLRV, but incompletely. Similarly, PLRV can establish an infection in mesophyll tissues and subsequently move into phloem tissues when co-inoculated with the umbravirus-like Pea enation mosaic virus RNA2 (Ryabov et al. 2001).

A nonstructural protein encoded by open reading frame (ORF) 4 of all members of the Polerovirus and Luteovirus genera has been suggested to play a role in cell-to-cell movement within phloem tissue. The PLRV 17-kDa protein (P17) has biochemical properties similar to the $30-\mathrm{kDa}$ movement protein of Tobacco mosaic virus (Citovsky and Zambryski 1991, 1993; Tomenius et al. 1987). P17 is phosphorylated in vivo, naturally forms a dimer, and two functional domains have been identified (Sokolova et al. 1997; Tacke et al. 1991, 1993). The basic C-terminal region of P17 protein contains a single-stranded nucleic acid binding domain, whereas the acidic $\mathrm{N}$-terminal region contains a dimerization domain and 
also contributes to interactions between P17 and host cell membranes (Tacke et al. 1991 1993). Furthermore, immunolocalization of P17 in naturally infected potato plants or P17expressing transgenic plants determined that the protein was present exclusively in phloem cells and was bound to plasmodesmata connecting companion cells to sieve tubes (Schmitz et al. 1997). Yet, the role of the PLRV P17 in virus movement remains ambiguous. The corresponding protein in the luteovirus Barley yellow dwarf virus-PAV was required for systemic infection in oat (Chay et al. 1996). However, the corresponding protein in the polerovirus Beet western yellows virus (BWYV) was not essential for systemic infection of Nicotiana clevelandii (Ziegler-Graff et al. 1996).

In this article, we provide evidence that the PLRV P17 is required for systemic infection of some, but not all, hosts. In addition, we determine its effects on virus movement and distribution within vascular tissues.

\section{RESULTS}

Host-dependent systemic infection of a P17-deficient PLRV.

The inoculation efficiency of the four plant species was assessed in potato (Solanum tuberosum cv. Desiree and cv. Russet Burbank), Physalis floridana, N. clevelandii, and N. benthamiana using suspensions of Agrobacterium tumefaciens harboring binary plasmids (referred to as agroinoculation) containing wild-type PLRV (pBNUP110) or PLRV expressing either of the two P17 mutants (pPLR $\Delta 17 \mathrm{~K}$ and pPLR $\triangle 4 N)$. Infection was determined by double-antibody sandwich enzyme-linked immunosorbent assay (DASELISA) of infiltrated leaves 2 weeks postinoculation (pi) and newly emerging leaves 3 to 6 weeks pi. Virus transcribed from pPLR $\triangle 17 \mathrm{~K}$ is not expected to express the P17 putative movement protein, and virus transcribed from pPLR $\Delta 4 \mathrm{~N}$ is expected to translate a modified P17 that does not contain the

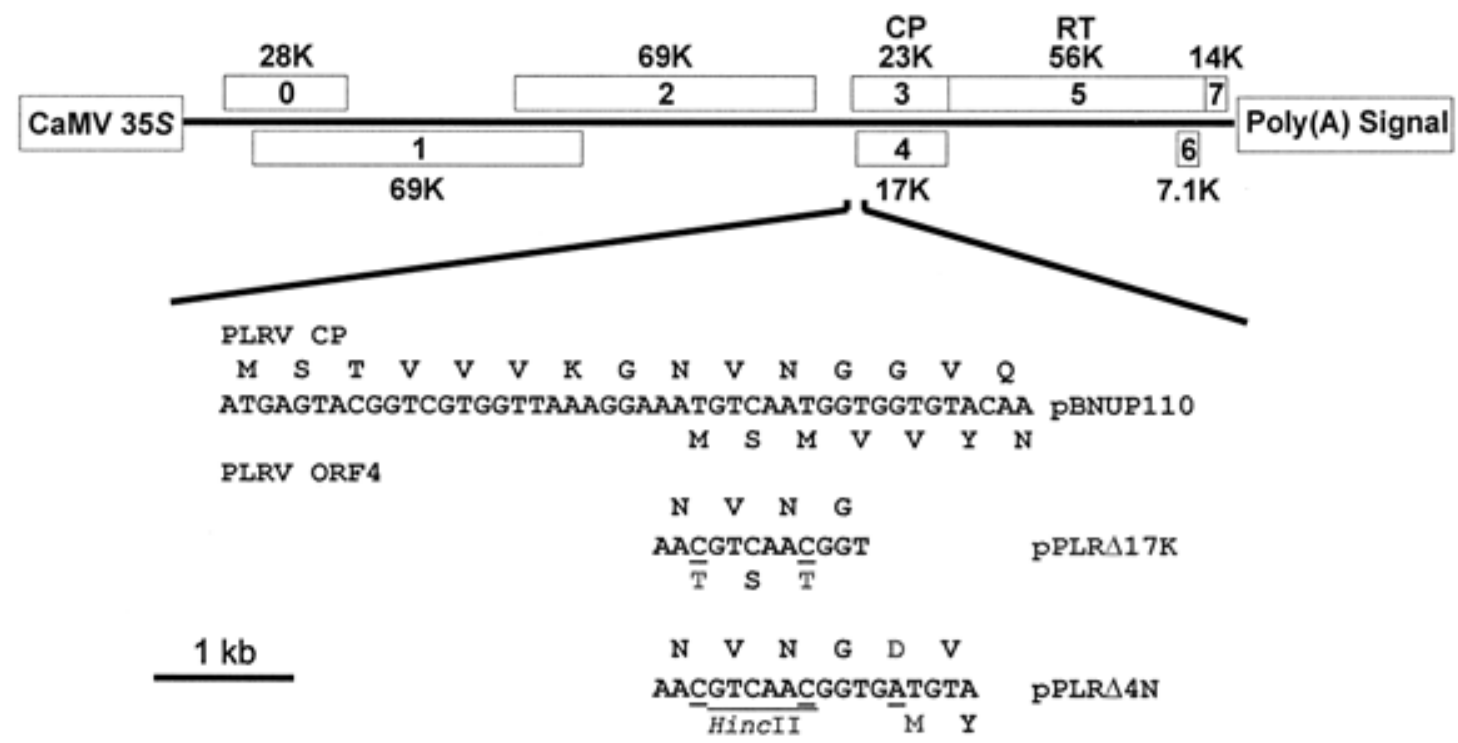

Fig. 1. Construction of Potato leafroll virus (PLRV) P17 mutants. Constructs of wild-type PLRV cDNA and open reading frame (ORF) 4 mutants are flanked by Cauliflower mosaic virus (CaMV) 35S promoter and polyadenylation signals. Site-directed mutagenesis was accomplished by overlapping polymerase chain reaction. PmlI/BstBI fragments containing ORF4 mutations were used to replace wild-type fragments in pUC.PLRV and pBNUP110. The scale is marked in nucleotides; boxes represent ORFs (ORF1 to 5); the solid line represents the PLRV cDNA sequence; $\mathrm{CP}=$ coat protein; $\mathrm{RT}=$ readthrough portion of $\mathrm{CP}$.

Table 1. Infection efficiency of wild-type and P17-deficient Potato leafroll virus (PLRV) in agroinoculated leaves and systemically infected tissues of Physalis floridana

\begin{tabular}{|c|c|c|c|c|c|c|}
\hline \multirow[b]{3}{*}{ Virus, leaves sampled $^{\mathrm{a}}$} & \multicolumn{6}{|c|}{ Experiment number } \\
\hline & \multicolumn{2}{|c|}{1} & \multicolumn{2}{|c|}{2} & \multicolumn{2}{|c|}{3} \\
\hline & Infection $^{\mathrm{b}}$ & Absorbance $^{\mathrm{c}}$ & Infection & Absorbance & Infection & Absorbance \\
\hline \multicolumn{7}{|l|}{ Wild type } \\
\hline Inoculated & $6 / 6$ & $2.17 \pm 0.68$ & $14 / 14$ & $2.08 \pm 0.70$ & $n d^{d}$ & nd \\
\hline New growth & $4 / 6$ & $1.39 \pm 0.76$ & $7 / 14$ & $1.95 \pm 0.66$ & $3 / 5$ & $1.26 \pm 0.25$ \\
\hline \multicolumn{7}{|l|}{ pPLR $\triangle 17 \mathrm{~K}$} \\
\hline Inoculated & $12 / 12$ & $1.17 \pm 0.56$ & $28 / 28$ & $1.16 \pm 0.52$ & nd & nd \\
\hline New growth & $0 / 12$ & $\ldots{ }^{d}$ & $0 / 28$ & $\ldots$ & $0 / 10$ & $\ldots$ \\
\hline \multicolumn{7}{|l|}{$\mathrm{pPLR} \triangle 4 \mathrm{~N}$} \\
\hline Inoculated & $6 / 6$ & $1.56 \pm 0.78$ & $14 / 14$ & $1.25 \pm 0.63$ & nd & nd \\
\hline New growth & $0 / 6$ & $\ldots$ & $0 / 14$ & $\ldots$ & $0 / 5$ & $\ldots$ \\
\hline
\end{tabular}

${ }^{\mathrm{a}}$ Three leaves were inoculated by injecting into the midrib $40 \mu \mathrm{l}$ of an Agrobacterium tumefaciens culture carrying the plasmid pBNUP110 (wild-type PLRV), pPLR $\triangle 17 \mathrm{~K}$ (produces a virus that does not translate the 17-kDa protein), or pPLR $44 \mathrm{~N}$ (produces a virus that translates a P17 missing the first four $\mathrm{N}$-terminal amino acids). Composite samples of three inoculated leaves were sampled at 2 weeks and several immature (new growth) leaves were sampled at 4 weeks post inoculation.

${ }^{\mathrm{b}}$ Number of leaf samples in which virus coat protein was detected/number of plants analyzed.

${ }^{c}$ Mean absorbance values $\left(\mathrm{A}_{405}\right) \pm$ standard deviation from double-antibody sandwich enzyme-linked immunosorbent assay detecting PLRV coat protein antigen.

${ }^{\mathrm{d}}$ nd $=$ no data and $\ldots=$ absorbance value not different from background. 
first four N-terminal amino acids (Fig. 1). The modification of the two ORF4 AUG codons present in pBNUP110 to ACG (pPLR $\triangle 17 \mathrm{~K}$ or pPLR $\Delta 4 \mathrm{~N}$ ) also created a HincII restriction site. This provided a convenient diagnostic marker for the modified viruses, which is not present in wild-type PLRV transcribed from pBNUP110. The ORF4 sequence encoding the P17 is completely contained within ORF3, which encodes the coat protein in a different reading frame. In pPLR $\triangle 17 \mathrm{~K}$, the wild-type coat protein sequence is retained. In pPLR $\Delta 4 \mathrm{~N}$, there is a single amino acid change in the coat protein sequence, a glycine to aspartic acid change at position 12.

PLRV accumulated in P. floridana leaves infiltrated with all three PLRV cDNA-containing plasmids (Table 1). Mean levels of virus coat protein were consistently higher in leaves infiltrated with wild-type virus than in leaves infiltrated with either P17 mutants; however, the differences were not significant $(P=$ $0.05)$ in all experiments. PLRV coat protein was detected in upper leaves from 14 out of 25 plants inoculated with pBNUP110, but none of the 50 or 25 plants inoculated with pPLR $\Delta 17 \mathrm{~K}$ or
pPLR $\triangle 4 \mathrm{~N}$, respectively, had detectable levels of PLRV coat protein in uninoculated leaves. Reverse-transcription polymerase chain reaction (RT-PCR) analyses of RNA extracted from apical leaves on a subset of the plants inoculated with pPLR $\Delta 17 \mathrm{~K}$ and pPLR $\triangle 4 \mathrm{~N}$ were negative for the presence of PLRV, and tissue immunoblot analysis (see below) did not detect any PLRV-infected cells in stem sections above the inoculated leaves (data not shown). Neither wild-type P17 protein nor modified P17 protein was detected from leaves inoculated with pBNUP110, pPLR $\triangle 17 \mathrm{~K}$, or pPLR $\triangle 4 \mathrm{~N}$ in any serological tests using available antibodies.

Similar results were obtained using two potato cultivars, Desiree and Russet Burbank. Virus coat protein was detected in leaves inoculated with all three viruses (Table 2), but only wild-type PLRV was able to initiate a systemic infection. One Russet Burbank potato plant inoculated with pPLR $\triangle 17 \mathrm{~K}$ and two inoculated with pPLR $\triangle 4 \mathrm{~N}$ did become systemically infected; however, subsequent analysis of the virus infecting these three plants indicated that the altered sequences had reverted to wild type (data not shown).

Table 2. Infection efficiency of wild-type and P17-deficient Potato leafroll virus (PLRV) in agroinoculated leaves and systemically infected tissues of two cultivars of potato, Solanum tuberosum ${ }^{\mathrm{a}}$

\begin{tabular}{|c|c|c|c|c|c|c|c|c|}
\hline \multirow[b]{3}{*}{ Virus, leaves sampled ${ }^{b}$} & \multicolumn{4}{|c|}{ cv. Russet Burbank } & \multicolumn{4}{|c|}{ cv. Desiree } \\
\hline & \multicolumn{2}{|c|}{ Exp. 1} & \multicolumn{2}{|c|}{ Exp. 2} & \multicolumn{2}{|c|}{ Exp. 1} & \multicolumn{2}{|c|}{ Exp. 2} \\
\hline & Infection $^{c}$ & Absorbance $^{\text {d }}$ & Infection & Absorbance & Infection & Absorbance & Infection & Absorbance \\
\hline \multicolumn{9}{|l|}{ Wild type } \\
\hline Inoculated & $11 / 11$ & $0.62 \pm 0.21$ & nd & nd & nd & nd & nd & nd \\
\hline New growth & $10 / 11$ & $1.86 \pm 0.62$ & $5 / 7$ & $1.00 \pm 0.51$ & $7 / 8$ & $0.47 \pm 0.18$ & $6 / 7$ & $0.60 \pm 0.44$ \\
\hline \multicolumn{9}{|l|}{ pPLR $\triangle 17 \mathrm{~K}$} \\
\hline Inoculated & $10 / 10$ & $0.40 \pm 0.16$ & nd & nd & nd & nd & nd & nd \\
\hline New growth & $0 / 10$ & $\ldots$ & $1 / 14$ & 1.06 & $0 / 10$ & $\ldots$ & $0 / 14$ & $\ldots$ \\
\hline \multicolumn{9}{|l|}{ pPLR $\triangle 4 N$} \\
\hline Inoculated & $5 / 5$ & $0.24 \pm 0.07$ & nd & nd & nd & nd & nd & nd \\
\hline New growth & $2 / 5$ & $0.95 \pm 0.34$ & $0 / 7$ & $\ldots$ & $0 / 5$ & $\ldots$ & $0 / 7$ & $\ldots$ \\
\hline
\end{tabular}

${ }^{\mathrm{a}}$ nd $=$ no data and $\ldots=$ absorbance value not different from background. Three leaves were inoculated by injecting into the midrib $40 \mu \mathrm{l}$ of an Agrobacterium tumefaciens culture carrying the plasmid pBNUP110 (wild-type PLRV), pPLRA17K (produces a virus that does not translate the 17-kDa protein), or pPLR $\triangle 4 \mathrm{~N}$ (produces a virus that translates a P17 protein missing the first four N-terminal amino acids).

${ }^{\mathrm{b}}$ Composite samples of three inoculated leaves were sampled at 2 weeks and several immature (new growth) leaves were sampled at 4 weeks post inoculation.

${ }^{c}$ Number of leaf samples in which virus coat protein was detected/number of plants inoculated.

${ }^{\mathrm{d}}$ Mean absorbance values $\left(\mathrm{A}_{405}\right) \pm$ standard deviation from double-antibody sandwich enzyme-linked immunosorbent assay detecting PLRV coat protein antigen.

Table 3. Infection efficiency of wild type and P17-deficient Potato leafroll virus (PLRV)in agroinoculated leaves and systemically infected tissues of Nicotiana benthamiana

\begin{tabular}{|c|c|c|c|c|c|c|}
\hline \multirow[b]{3}{*}{ Virus, leaves sampled $^{a}$} & \multicolumn{6}{|c|}{ Experiment number } \\
\hline & \multicolumn{2}{|c|}{1} & \multicolumn{2}{|c|}{2} & \multicolumn{2}{|c|}{3} \\
\hline & Infection $^{b}$ & Absorbance $^{c}$ & Infection & Absorbance & Infection & Absorbance \\
\hline \multicolumn{7}{|l|}{ Wild type } \\
\hline Inoculated & $10 / 10$ & $1.20 \pm 0.72$ & $8 / 8$ & $0.93 \pm 0.72$ & $n d^{d}$ & nd \\
\hline New growth & $10 / 10$ & $0.45 \pm 0.13$ & $8 / 8$ & $0.84 \pm 0.48$ & $10 / 10$ & $1.54 \pm 1.07$ \\
\hline New growth & $10 / 10$ & $1.35 \pm 0.51$ & $8 / 8$ & $0.52 \pm 0.16$ & $10 / 10$ & $1.47 \pm 0.92$ \\
\hline \multicolumn{7}{|l|}{ pPLR $\triangle 17 \mathrm{~K}$} \\
\hline Inoculated & $9 / 10$ & $0.82 \pm 0.61$ & $7 / 10$ & $0.78 \pm 0.80$ & nd & nd \\
\hline New growth & $6 / 10$ & $0.37 \pm 0.13$ & $6 / 10$ & $1.12 \pm 0.91$ & $5 / 5$ & $0.59 \pm 0.36$ \\
\hline New growth & $6 / 10$ & $0.75 \pm 0.37$ & $6 / 10$ & $0.75 \pm 0.37$ & $5 / 5$ & $0.35 \pm 0.13$ \\
\hline \multicolumn{7}{|l|}{$\mathrm{pPLR} \triangle 4 \mathrm{~N}$} \\
\hline Inoculated & $10 / 10$ & $0.57 \pm 0.36$ & $9 / 10$ & $0.55 \pm 0.36$ & nd & nd \\
\hline New growth & $10 / 10$ & $0.33 \pm 0.13$ & $9 / 10$ & $0.59 \pm 0.31$ & $10 / 10$ & $0.59 \pm 0.36$ \\
\hline New growth & $10 / 10$ & $0.59 \pm 0.27$ & $9 / 10$ & $0.65 \pm 0.25$ & $10 / 10$ & $0.35 \pm 0.13$ \\
\hline
\end{tabular}

${ }^{\mathrm{a}}$ Three leaves were inoculated by injecting into the midrib $40 \mu \mathrm{l}$ of an Agrobacterium tumefaciens culture carrying the plasmid pBNUP110 (wild-type PLRV), pPLR $\triangle 17 \mathrm{~K}$ (produces a virus that does not translate the $17-\mathrm{kDa}$ protein), or pPLR $4 \mathrm{~N}$ (produces a virus that translates a P17 protein missing the first four $\mathrm{N}$-terminal amino acids). Composite samples of three inoculated leaves were sampled at 2 weeks and several immature (new growth) leaves were sampled at 3 and 4 weeks post inoculation.

${ }^{\mathrm{b}}$ Number of leaf samples in which virus coat protein was detected/number of plants inoculated.

${ }^{c}$ Mean absorbance values $\left(\mathrm{A}_{405}\right) \pm$ standard deviation from double-antibody sandwich enzyme-linked immunosorbent assay detecting PLRV coat protein antigen.

$\mathrm{d}$ nd = no data. 
In contrast to potato and $P$. floridana, both Nicotiana spp. could be systemically infected by the two P17 mutants as well as by wild-type PLRV (Tables 3 and 4). Relative amounts of virus coat protein were variable in inoculated and systemically infected leaves of $N$. benthamiana plants infected by wild-type PLRV or either of the P17 mutants but, in most plants, virus was detectable and continued to accumulate throughout the experiment (Table 3). Coat protein accumulated in the agroinoculated leaves of $N$. clevelandii plants inoculated with all three viruses, but only 60 and $20 \%$ of plants inoculated with pPLR $\Delta 17 \mathrm{~K}$ and pPLR $\Delta 4 \mathrm{~N}$, respectively, became infected systemically, whereas $95 \%$ of the plants inoculated with wild-type virus became infected systemically (Table 4). Furthermore, coat protein levels in plants infected systemically with any of the three viruses were relatively low and decreased as the plants aged. This was most noticeable in plants infected with pPLR $\triangle 4 \mathrm{~N}$, in which virus coat protein was not detectable in any plant 4 weeks pi. There was no evidence that either of the P17 mutants had reverted to wild-type virus in systemically infected plants of either Nicotiana spp. (data not shown).

\section{Tissue immunoblot analysis of plants infected systemically with PLRV P17 mutants.}

To further examine the role of the PLRV P17 in the systemic infection of plants, the spatial distribution of virus in stem and leaf petiole tissues at various times postinoculation was determined using tissue immunoblot analysis (Figs. 2 and 3). Tissue prints of leaf petioles and stems from every node as well as the apex were generated at 3 weeks pi from five agroinoculated $N$. benthamiana plants for each virus construct. Tissue prints also were made of cross-sections of some inoculated leaves. The experiment was repeated at least twice for each construct. PLRV coat protein in infected cells was visualized on tissue blots as stained foci of indoxyl precipitate. No cross-reaction of the PLRV antibody with host proteins was observed in noninfected plant tissues (Fig. 2C, D, and G). The outlines of most cells were discernable on the blots when visualized under a dissecting microscope, allowing the precise location of infected cells to be identified and counted (Fig. 2E and F). In the agroinoculated leaf, virus coat protein was detected in all cell types in leaves infiltrated with pBNUP110, pPLR $\Delta 17 \mathrm{~K}$, and $\mathrm{pPLR} \triangle 4 \mathrm{~N}$, confirming that virus was able to accumulate in mesophyll cells (Fig. $2 \mathrm{H}$ through $\mathrm{J}$ ). Whereas, in systemically infected leaves, virus is detected only in phloem tissue (Fig. 2K).

In plants agroinoculated with wild-type PLRV, virus accumulated in the internal and external phloem in petioles of inoculated leaves (Fig. 3E and F) as well as in petioles of uninoculated leaves and stem sections above and below the inoculated leaves (Fig. 3C, D, G, and H), and in apical tissues (Fig. 3A and B). In plants agroinoculated with the pPLR $\triangle 17 \mathrm{~K}$ or pPLR $\triangle 4 \mathrm{~N}$ mutants, virus accumulated to similar levels as in wild-type PLRV in the apical leaves (compare Fig. 3I, J, Q, and R with A and B), but not in older tissues. It is notable that the P17 mutants were not detected in petioles or lamina tissue of mature leaves located immediately above or below the inoculated leaves (Fig. 3K, O, S, and $\mathrm{W}$ and Fig. 4). The spatial distribution of both P17 mutants was similar, based on the tissue immunoblot analysis (Fig. 3I through $\mathrm{P}$ and $\mathrm{Q}$ through $\mathrm{X}$ ).

A closer examination of the number of PLRV-infected cells within the vascular tissues of the leaf petioles and main stem revealed that wild-type PLRV accumulated in more phloem cells in all tissues (leaf, petiole, and stem) compared with the P17 mutants, except in the youngest leaves or apical tissue (Fig. 4). Furthermore, wild-type virus accumulated in more external than internal phloem cells of inoculated leaf petioles and stem sections below the inoculated leaves. In contrast, the pPLR $\triangle 17 \mathrm{~K}$ and pPLR $\Delta 4 \mathrm{~N}$ mutants were detected in fewer phloem cells of stem and petioles and were not observed in the petioles of uninoculated leaves located either below or immediately above the agroinoculated leaves (Fig. 4). These leaves would have been mature leaves at the time of the agroinoculation. In the main stem, the pPLR $\Delta 17 \mathrm{~K}$ and pPLR $\Delta 4 \mathrm{~N}$ mutants accumulated mainly in the external phloem cells. Overall, the distribution of infected cells in the stem adjacent to leaves present on the plant at the time of inoculation was approximately $70 \%$ of the outer phloem to $30 \%$ of the inner phloem, but this distribution was not maintained in new growth regions (i.e., Fig. 4, leaf positions 2 through 6). Furthermore, the distribution of wild-type PLRV and the pPLR $\triangle 17 \mathrm{~K}$ and pPLR $\triangle 4 \mathrm{~N}$ mutants became increasingly more similar in upper stem segments.

Table 4. Infection efficiency of wild type and P17-deficient Potato leafroll virus (PLRV) in agroinoculated leaves and systemically infected tissues of Nicotiana clevelandii

\begin{tabular}{|c|c|c|c|c|c|c|}
\hline \multirow[b]{3}{*}{ Virus, leaves sampled ${ }^{a}$} & \multicolumn{6}{|c|}{ Experiment number } \\
\hline & \multicolumn{2}{|c|}{1} & \multicolumn{2}{|c|}{2} & \multicolumn{2}{|c|}{3} \\
\hline & Infection $^{b}$ & Absorbance ${ }^{c}$ & Infection & Absorbance & Infection & Absorbance \\
\hline \multicolumn{7}{|l|}{ Wild type } \\
\hline Inoculated & $9 / 10$ & $1.20 \pm 0.43$ & $4 / 5$ & $1.44 \pm 1.00$ & $8 / 8$ & $0.94 \pm 0.46$ \\
\hline New growth & $9 / 10$ & $0.34 \pm 0.10$ & $4 / 5$ & $0.85 \pm 0.74$ & $7 / 8$ & $0.27 \pm 0.15$ \\
\hline New growth & $9 / 10$ & $0.17 \pm 0.07$ & $4 / 5$ & $0.24 \pm 0.10$ & $7 / 8$ & $0.29 \pm 0.20$ \\
\hline \multicolumn{7}{|l|}{ pPLR $\triangle 17 \mathrm{~K}$} \\
\hline Inoculated & $10 / 10$ & $1.60 \pm 0.87$ & $5 / 5$ & $1.63 \pm 0.80$ & $10 / 10$ & $0.99 \pm 0.76$ \\
\hline New growth & $6 / 10$ & $0.36 \pm 0.11$ & $2 / 5$ & $0.26 \pm 0.01$ & $7 / 10$ & $0.50 \pm 0.39$ \\
\hline New growth & $6 / 10$ & $0.18 \pm 0.05$ & $2 / 5$ & $0.10 \pm 0.00$ & $7 / 10$ & $0.23 \pm 0.18$ \\
\hline \multicolumn{7}{|l|}{$\mathrm{pPLR} \triangle 4 \mathrm{~N}$} \\
\hline Inoculated & $9 / 10$ & $1.16 \pm 0.66$ & $4 / 5$ & $1.02 \pm 0.63$ & $7 / 10$ & $0.91 \pm 0.50$ \\
\hline New growth & $2 / 10$ & $0.33 \pm 0.10$ & $1 / 5$ & 0.39 & $1 / 10$ & 0.39 \\
\hline New growth & $0 / 10$ & $\ldots^{d}$ & $0 / 5$ & $\ldots$ & $0 / 10$ & $\ldots$ \\
\hline
\end{tabular}

${ }^{\mathrm{a}}$ Three leaves were inoculated by injecting into the midrib $40 \mu \mathrm{l}$ of an Agrobacterium tumefaciens culture carrying the plasmid pBNUP110 (wild-type PLRV), pPLR $17 \mathrm{~K}$ (produces a virus that does not translate the $17-\mathrm{kDa}$ protein), or pPLR $\triangle 4 \mathrm{~N}$ (produces a virus that translates a P17 protein missing the first four $\mathrm{N}$-terminal amino acids). Composite samples of three inoculated leaves were sampled at 2 weeks and several immature (new growth) leaves were sampled at 3 and 4 weeks post inoculation.

${ }^{\mathrm{b}}$ Number of leaf samples in which virus coat protein was detected/number of plants inoculated.

${ }^{c}$ Mean absorbance values $\left(\mathrm{A}_{405}\right) \pm$ standard deviation from double-antibody sandwich enzyme-linked immunosorbent assay detecting PLRV coat protein antigen.

$\mathrm{d} \ldots=$ absorbance value not different from background. 
Time course analysis of virus movement in $N$. benthamiana.

Tissue immunoblot analysis was used to detect virus in a time-course comparison of infection by wild-type PLRV and the pPLR $\triangle 17 \mathrm{~K}$ mutant (Table 5). Two agroinoculated plants were examined for each construct at each time point. Tissue prints were taken of leaf petioles and stems from every node as well as the apex of each plant at 1-day intervals (1 to 14 days pi) and at 21 days pi. The experiments were repeated twice for each construct. At 3 days pi, both viruses were detected in the agroinfiltrated areas of the inoculated leaf. Wild-type PLRV was found to spread into the petioles of the inoculated leaves more quickly than the pPLR $\Delta 17 \mathrm{~K}$ mutant virus. At 5 days pi, wild-type PLRV was observed in the vascular bundles of the agroinoculated leaf petiole and in stem sections above the inoculated leaves, as well as in apical tissues. By 6 days pi, wildtype PLRV was observed in the stem below the agroinoculation site and, within 14 to 21 days pi, infected cells were observed in the petioles of all the leaves below the inoculated leaves. In contrast, it was 7 days pi before the pPLR $\Delta 17 \mathrm{~K} \mathrm{mu-}$ tant virus was detected in the petioles of the agroinoculated leaf and 8 days pi before the virus had moved into stem and petiole tissues above the inoculated leaves. The pPLR $\Delta 17 \mathrm{~K}$ mutant virus was detected in the stem below the agroinoculation site within 14 to 21 days pi, but virus was not detected in the petioles of mature lower leaves, even by 21 days pi.

\section{DISCUSSION}

The PLRV P17 apparently is required for systemic infection of potato and $P$. floridana, whereas the protein is not required or is not functional in the systemic movement of PLRV in the two Nicotiana spp. that commonly are used as propagation hosts of many viruses. Interestingly, when a mutation similar to pPLR $\triangle 17 \mathrm{~K}$ was made in the corresponding protein in the PAV strain of Barley yellow dwarf virus, the P17-deficient virus was unable to systemically infect oat plants (Chay et al. 1996). In contrast, a similar mutation in the analogous $19-\mathrm{kDa}$ protein of BWYV did not prevent the virus from establishing a systemic infection in the propagation host, $N$. clevelandii (Ziegler-Graff et al. 1996). Thus, the requirement of the P17 putative movement protein appears to be host dependent.

We were unable to confirm the expected changes in translation of the P17 protein from pPLR $\triangle 17 \mathrm{~K}$ or pPLR $\triangle 4 \mathrm{~N}$ using available antibodies. However, mutations analogous to those in pPLR $\triangle 17 \mathrm{~K}$ in other luteoviruses, including other isolates of PLRV, have eliminated the translation of the P17 (Chay et al. 1996; Prüfer et al. 1997; Ziegler-Graff et al. 1996). Changes in P17 had no notable effects on virus accumulation, virus assembly, or aphid transmission. Furthermore, the P17 mutation was maintained in the agroinoculated leaves and systemically infected leaves, as confirmed by sequencing of immunocapture RT-PCR products. The mutant, pPLR $\triangle 4 \mathrm{~N}$ would be expected to
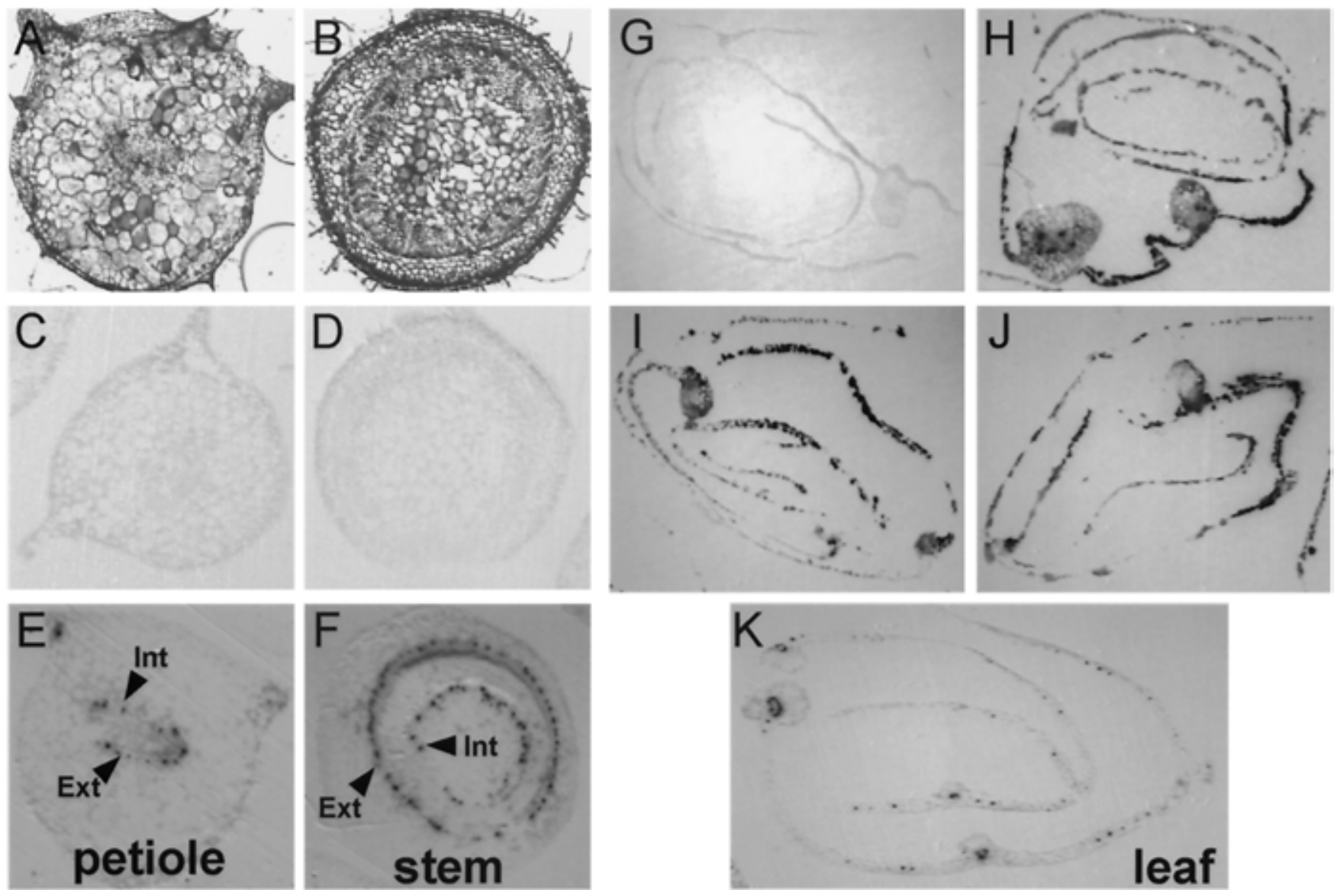

Fig. 2. Detection of Potato leafroll virus (PLRV) in tissue prints of petioles, stems, and leaves of Nicotiana benthamiana plants. Cross-sections: A, petiole and $\mathbf{B}$, stem tissue showing the gross morphology of tissue and cell structure for reference. Tissue prints: petiole cross-sections from $\mathbf{C}$, leaves mockinoculated with water or E, leaves agroinoculated with PLRV (pBNUP110) and developed with antibodies to PLRV; stem cross-sections from stem immediately below leaves D, mock-inoculated with water or F, agroinoculated with pBNUP110 (PLRV) and developed with antibodies to PLRV; leaves G, mockinoculated with water or agroinoculated with $\mathbf{H}$, wild-type PLRV or I, P17 mutants PLRA17K or J, PLR 4 N. K, Tissue print from a leaf systemically infected with PLRV and developed with antibodies to PLRV. The prints were photographed under a microscope at a magnification of $\times 10$ to $\times 35$. The presence of PLRV is visualized as blue-stained foci of indoxyl precipitate. Arrows indicate internal (Int) and external (Ext) phloem. 
translate a P17 missing only the first four N-terminal amino acids yet, biologically, it behaves more like pPLR $\Delta 17 \mathrm{~K}$ than like the wild-type virus. The four missing amino acids may be critical for protein function, protein folding, or, alternatively, the poor context of the initiation codon may reduce or eliminate translation of the truncated P17 (Kozak 1989). No reports have described deletions or mutations in the extreme $\mathrm{N}$-terminus of luteovirus movement proteins, but possible effects could include changes to the P17 dimerization, phosphorylation, or localization to plasmodesmata (Tacke et al. 1993). Also, the mutation in pPLR $\triangle 4 \mathrm{~N}$ involves a single amino acid change in the PLRV coat protein, which may contribute to the observed phenotype.

Although both P17 mutant viruses replicate and assemble virions similar to wild-type virus in potato and P. floridana, the virus appears to be unable to efficiently accumulate in phloem tissue within the petiole of inoculated leaves or to reach the main phloem tissues of the stem. In the Solanaceae and a few other plant families, major veins of leaves contain abaxial and adaxial phloem that become the external and internal phloem, respectively, in the transport veins of petioles and stems. This structural differentiation has consequences for photoassimilate transport, although their effect on virus transport is not fully understood. (Derrick and Nelson 1999; Turgeon 1989). Our examination using tissue immunoblots of virus movement and distribution within tissues of $N$. benthamiana indicated that PLRV moved initially upward to apical tissue, presumably through internal phloem, and then downward to more mature tissue, presumably in the external phloem. Similarly, the infection of $N$. benthamiana by the P17 mutants proceeded from the inoculated leaves upward to apical tissue, but accumulated in significantly fewer phloem cells. In particular, the P17 mutants were unable to accumulate in the petioles of the mature leaves, but did accumulate in the younger, apical tissue.

Restriction of virus from entering specific tissues has been described as a plant resistance response for other viruses (Derrick and Barker 1997; Dufour et al. 1989; Guerini and Murphy 1999). A phloem-associated resistance was identified in Capsicum spp. against Cucumber mosaic virus (CMV) (Dufour et al. 1989). In the susceptible cultivar, CMV was detected above and below the inoculation site and in both the internal and external phloem of the petiole. CMV spread into the stem of the resistant host but remained below the inoculation site and was localized to external phloem (Dufour et al. 1989). Similarly, the potyvirus Pepper mottle virus Florida isolate (PepMoV-FL) accumulated in the external phloem of resistant Capsicum annuum cv. Avelar plants, yet was unable to move upward from the inoculation site (Guerini and Murphy 1999). The pathway of translocation for PepMoV-FL was described as following the flow of photoassimilates, occurring initially in external phloem moving downward in a susceptible host $C$.

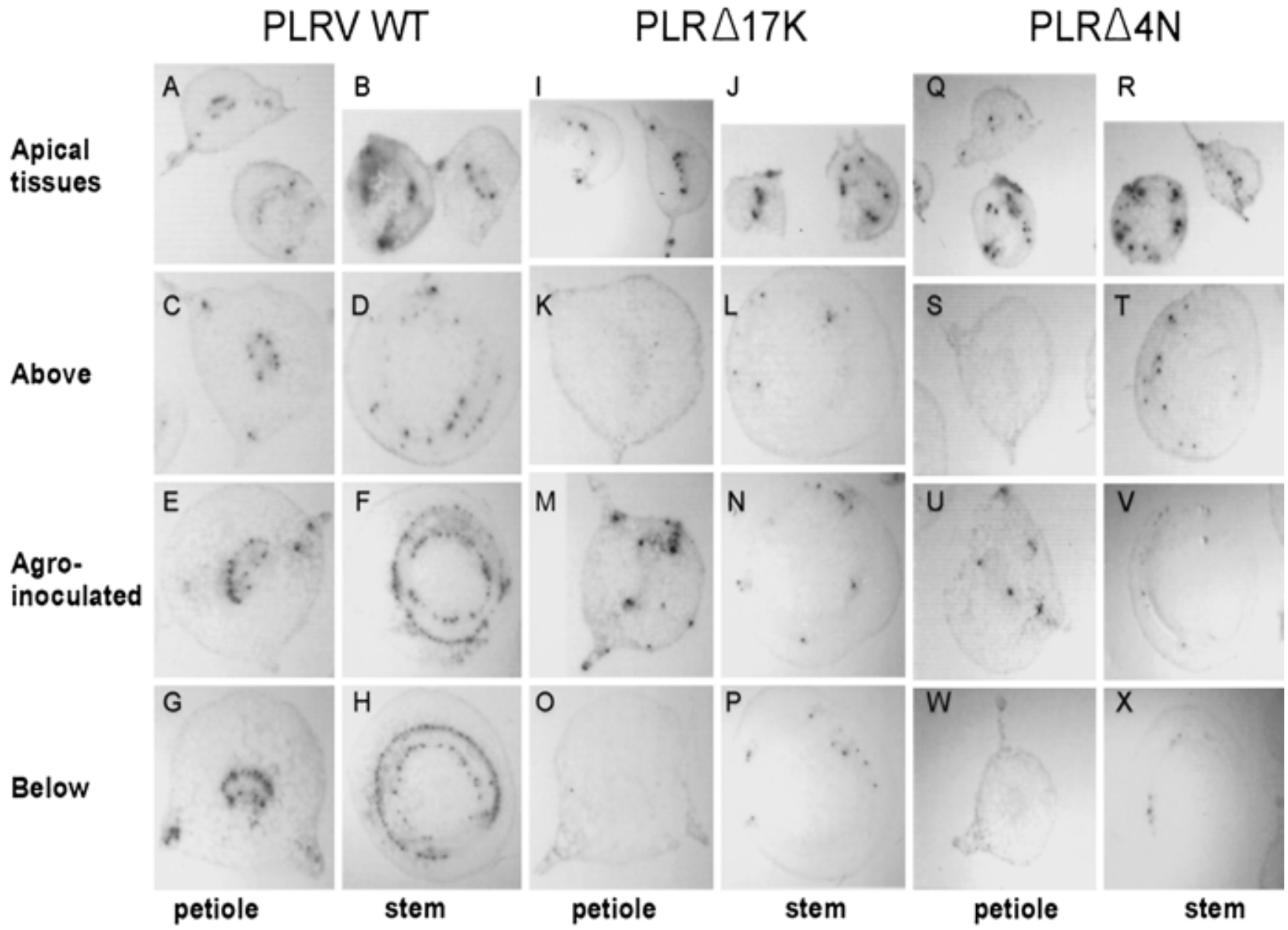

Fig. 3. Immunoprints of petiole and stem tissue from various locations on Nicotiana benthamiana plants systemically infected with wild-type Potato leafroll virus (PLRV WT) or P17 mutants (PLR $17 \mathrm{~K}$ and pPLRA4). E, F, M, N, U, and V, Immunoprints from petioles of an agroinoculated leaf and a stem section immediately below that petiole; petioles and associated adjacent stem sections from uninoculated leaves $\mathbf{G}, \mathbf{H}, \mathbf{O}, \mathbf{P}, \mathbf{W}$, and $\mathbf{X}$, below and $\mathbf{C}, \mathbf{D}, \mathbf{K}, \mathbf{L}, \mathbf{S}$, and $\mathbf{T}$, above the inoculated leaf. Also shown are immunoprints of petioles and associated stems of apical leaves from plants infected with $\mathbf{A}$ and $\mathbf{B}$, wild-type PLRV and I, J, Q, and R, P17 mutant viruses. Tissue prints were developed with antibodies to PLRV and virus was visualized as blue-stained foci of indoxyl precipitate. The prints were photographed under a microscope at a magnification of $\times 10$ to 35 . 
annuum cv. Early Cal Wonder, and then proceeding into internal phloem, moving upward to infect this host systemically (Andrianifahanana et al. 1997). These observations are consistent with their hypothesis that virus moves up the stem in internal phloem and down the stem in external phloem. Guerini and Murphy (1999) suggested that PepMoV-FL was unable to enter the inner phloem of the resistant $C$. annuum cv. Avelar.

Derrick and Barker (1997) have investigated the localization of PLRV in potato cultivars possessing natural or transgenic resistance to PLRV manifested as a reduction in virus accumulation. In the resistant genotypes, PLRV accumulated in the inner phloem but was excluded from the external phloem. It was suggested that PLRV movement was impaired from moving from sieve elements to companion cells, thus reducing the number of external phloem cells that became infected in the resistant. In this study, the P17 mutants of PLRV appeared to be able to move systemically to apical tissues in $N$. benthamiana plants, but were not restricted from accumulation in the phloem, except in more mature tissues. Thus, there may be two pathways for PLRV translocation in $N$. benthamiana, similar to that proposed for BWYV in N. clevelandii (Ziegler-Graff et al. 1996): a P17independent pathway involving PLRV translocation in internal phloem and a P17-dependent pathway involving translocation in external phloem. However, this is clearly a host-dependent phenomenon because, in potato and $P$. floridana, the virus appears to be unable to move into the internal or external phloem in the main stem and systemically infect the plants. Alternatively, short-distance movement between sieve elements and companion cells was mediated by PLRV-encoded P17, as proposed by Derrick and Barker (1997). In their study, long-distance movement through sieve elements of resistant potato clones seemed to occur at the same rate as in tissue from susceptible clones. However, in resistant plants, short-distance movement is dramatically impaired, with the result that fewer cells in the external phloem become infected. Thus, the product of this resistance may act directly against the P17, possibly by inactivating or inhibiting its expression, and appears to be more effective in the external phloem (Derrick and Barker 1997).

Clearly, there are untested hypotheses in this model. It is not known if there is a differential distribution or expression of PLRV P17 in internal and external phloem. Further work also is needed to investigate whether the pattern of translocation for wild-type PLRV is similar in potato and $P$. floridana, as it is for $N$. benthamiana and $N$. clevelandii; that is, upward systemic movement through the internal phloem and downward movement through the external phloem.

\section{MATERIALS AND METHODS}

\section{Recombinant plasmids.}

Plasmid pBNUP110 and pUC.PLRV were described previously and both contain a full-length cDNA copy of PLRV
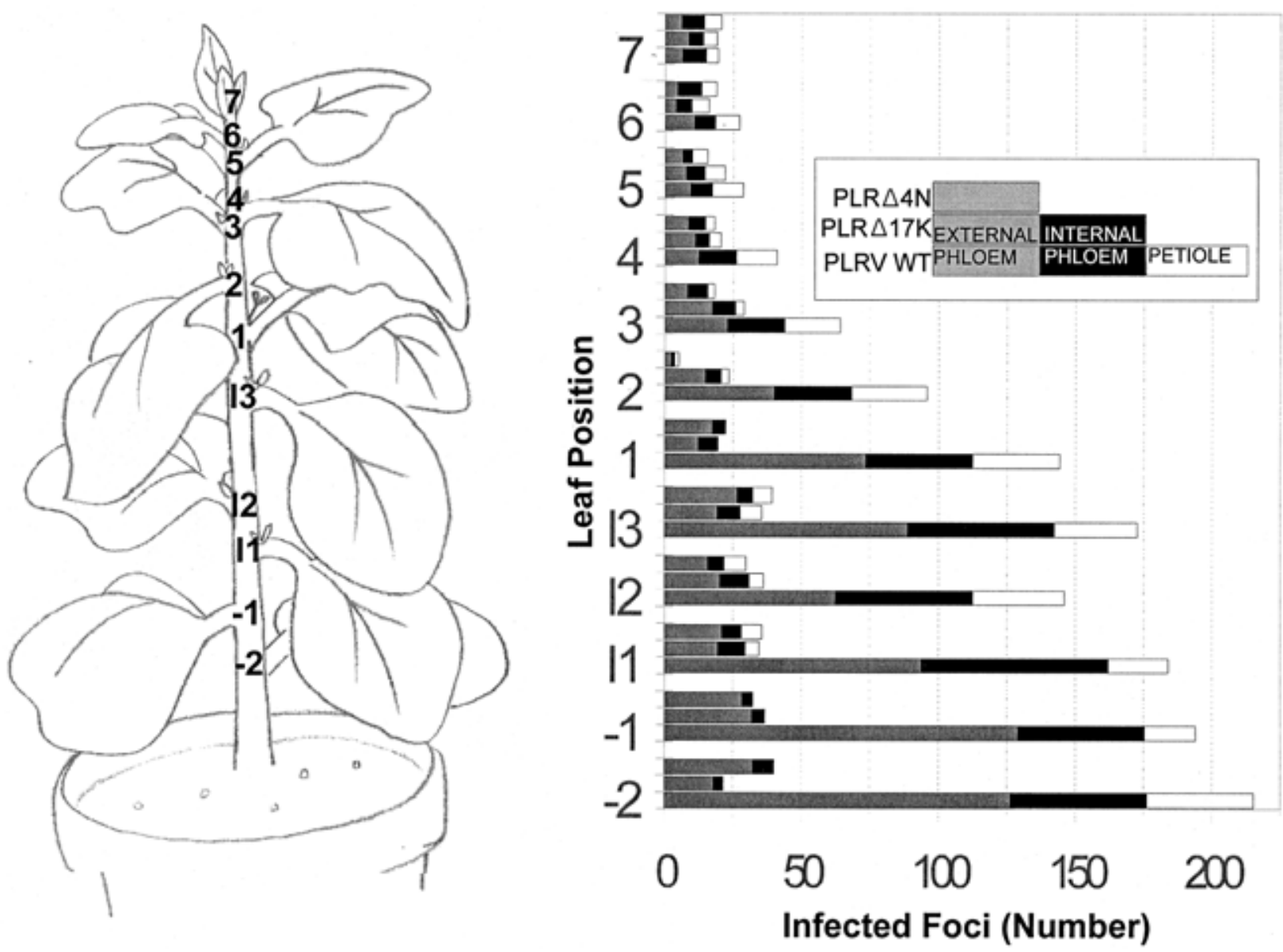

Fig. 4. Wild-type Potato leafroll virus (PLRV) and P17 mutant virus distribution in internal and external phloem of stem tissue and in petioles of systemically infected Nicotiana benthamiana plants. The leaf panel depicts the tissue sample locations. Virus was visualized in a petiole cross-section and a stem cross-section immediately above the petiole for each leaf position. Leaves I1, I2, and I3 were agroinoculated with virus 3 weeks prior to sampling. Leaf positions -1 to -2 are the nodes below the inoculated leaves and leaves 1 to 7 are those nodes above the inoculated leaves. The right panel shows a graphic representation of the number of virus-infected cells visualized as blue-stained foci of indoxyl precipitate in the immunoprint cross-sections photographed under a microscope. Stained foci were counted separately in the internal and external phloem in the stem, but the two tissue types could not be reliably differentiated in the petiole sections. 
(Canadian isolate) between the Cauliflower mosaic virus $35 \mathrm{~S}$ RNA promoter and the corresponding transcription termination signal sequence (Commandeur and Martin 1993; FrancoLara et al. 1999; Nurkiyanova et al. 2000). The pUC.PLRV plasmid contains the pUC118 backbone and was used as an intermediate for ease of cloning (high copy number) and the pBNUP110 plasmid contains the pBIN19 backbone, which is the disarmed Ti plasmid used for agroinoculation (Frisch et al. 1995). Site-directed mutagenesis was accomplished by overlapping PCR using the pUC.PLRV as template and the following primer pairs: PLRV5'p3438 (corresponding to PLRV nucleotides 3,438-3,461)/PLRV17kMut3' (5'-caccGttgacGtttcctttaaccacgaccg-3', which is complimentary to PLRV nucleotides 3,596-3,625, except the adenine residues at positions 3,615 and 3,621 were changed to guanine) and PLRV17kMut5' (5'- ggaaaCgtcaaCggtggtgtacaacaaccaagaagg$3^{\prime}$, identical to PLRV nucleotides 3,610-3,645, with the exception of a change at 3,615 and 3,621 from thymine to cytosine)/PLRTH1R (complimentary to PLRV nucleotides 4,8694,897). A PmlI-BstBI fragment corresponding to PLRV nucleotides 3,572-4,636 was released from the PCR product and used to replace the similar PmlI-BstBI fragment of pUC.PLRV. After the region corresponding to the PLRV coat protein/P17 region (nucleotides 3,461-4,248) was sequenced, the PmlIXhoI fragment (nucleotide 3,572-5,482 in the PLRV RNA sequence) of pUC.PLRV was used to replace the PmlI-XhoI fragment of pBNUP110. The clones that resulted contained altered initiation codons in ORF4 and an additional HincII restriction site (underlined in primer sequence) useful for screening the clones. Clone pPLR $\triangle 17 \mathrm{~K}$ contained the expected mutations (both AUGs changed to ACG), but clone pPLR $\triangle 4 \mathrm{~N}$ contained an additional mutation, presumably that arose during the PCR, that resulted in an in-frame AUG downstream within the ORF4 coding sequence (Fig. 1).

\section{Agroinoculation and virus detection.}

Agrobacterium tumefaciens LBA4404 strains carrying pBNUP110, pPLR $\Delta 17 \mathrm{~K}$, or pPLR $\triangle 4 \mathrm{~N}$ were grown in yeast extract beef broth with kanamycin $(50 \mu \mathrm{g} / \mathrm{ml})$ for $48 \mathrm{~h}$. The culture was centrifuged and resuspended in 1/10 volume of water and used for agroinfection of $N$. benthamiana and $N$. clevelandii plants at the 5- to 6-leaf stage (Leiser et al. 1992; Nurkiyanova

Table 5. Time-course analysis of Potato leafroll virus (PLRV) infection in Nicotiana benthamiana

\begin{tabular}{lcc}
\hline & $\begin{array}{c}\text { Days post inoculation } \\
\text { when PLRV infection } \\
\text { first detected }\end{array}$ \\
\cline { 2 - 3 } Tissue type & 3 & 3 \\
pBNUP110 & pPLRA17K $^{\text {a }}$ \\
\hline Agroinoculated leaf & 5 & 7 \\
Petiole of agroinoculated leaf & 5 & 8 \\
Stem immediately above agroinoculated leaf & 5 & ND \\
Petiole immediately above agroinoculated leaf & 5 & 8 \\
Stem above agroinoculated leaf & 5 & 8 \\
Petiole above agroinoculated leaf & 5 & 8 \\
Apical leaf & 5 & 8 \\
Apical stem & 6 & $14-21$ \\
Stem below agroinoculated leaf & $14-21$ & ND \\
Petiole below agroinoculated leaf & 5 \\
a $\begin{array}{l}\text { Detection by tissue immunoblot. Two agroinoculated plants were } \\
\text { examined for each construct and each time point. Tissue prints were }\end{array}$ \\
taken of leaf petioles and stems from every node as well as the apex of \\
each plant at 1-day intervals post inoculation (1 to 14 days) and at 21 \\
days post inoculation. These were repeated at least twice for each \\
construct. Virus was determined to be present when three or more \\
stained foci of indoxyl precipitate were identified in tissue prints from \\
cross-sections of leaf petioles and stems. ND = not detected; 14-21 = \\
between 14 and 21 days.
\end{tabular}

et al. 2000). Approximately $40 \mu \mathrm{l}$ of Agrobacterium suspension was injected using a Hamilton syringe into the midrib of each leaf (three in all). Inoculated plants were placed at $20^{\circ} \mathrm{C}$ for 7 days prior to being placed in the greenhouse.

The accumulation of PLRV was assessed by detection of viral coat protein using DAS-ELISA (Agdia, Inc., Elkhart, IN), essentially as described previously (Barker and Solomon 1990). Leaves from agroinoculated plants were sampled at weekly intervals beginning at 2 weeks and up to 6 weeks. The progeny viruses, from systemically infected plants, were analyzed by RT-PCR followed by screening for the additional HincII restriction enzyme site.

\section{Tissue immunoblot analysis.}

The blotting procedure was as described by Andrianifahanana and associates (1997). For petioles and stems, single cuts were made across their axes. The cut surface of the tissue was pressed directly onto nitrocellulose membranes (Schleicher and Schuell, Inc., Keene, NH) that were treated with $0.2 \mathrm{M} \mathrm{CaCl}_{2}$ prior to blotting. Tissue prints were allowed to air dry and stored at $4^{\circ} \mathrm{C}$ until the end of the experiment, at which time the samples were analyzed under the same conditions. PLRV coat protein was detected in tissue blots using anti-PLRV immunoglobin as primary antibody $(1 \mu \mathrm{g} / \mathrm{ml})$, monoclonal antibody SCR3 diluted 1:5000 (Torrance 1992), and goat anti-mouse immunoglobulin conjugated to alkaline phosphatase (1:5000) as secondary antibody. The presence of alkaline phosphatase was detected using the 1-Step NBT/BCIP system (Pierce, Rockford, IL).

Tissue immunoblot analysis was used to detect virus in a time-course comparison of infection by wild-type PLRV and the pPLR $\triangle 17 \mathrm{~K}$ mutant. Two agroinoculated plants were examined for each construct and each time point. Tissue prints were taken of leaf petioles and stems from every node as well as the apex of each plant at 1-day intervals ( 1 to 14 days pi) and at 21 days pi. The experiments were repeated at least twice for each construct. Virus was determined to be present when three or more stained foci of indoxyl precipitate were identified in tissue prints from cross-sections of leaf petioles and stems.

\section{ACKNOWLEDGMENTS}

This work was partially supported by NRICGP grant 96-35303-3196, an ARS Postdoctoral Research Associate Award, and a grant-in-aid from the Scottish Executive Environment and Rural Affairs Department. We thank D. Smith and D. Liang for technical assistance and helpful discussion.

\section{LITERATURE CITED}

Andrianifahanana, M., Lovins, K., Dute, R., Sikora, E., and Murphy, J. F. 1997. Pathway for phloem-dependent movement of pepper mottle potyvirus in the stem of Capsicum annuum. Phytopathology 87:892898.

Barker, H. 1987. Invasion of non-phloem tissue in Nicotiana clevelandii by potato leafroll luteovirus is enhanced in plants also infected with potato Y potyvirus. J. Gen. Virol. 68:1223-1227.

Barker, H. 1989. Specificity of the effect of sap transmissible viruses in increasing the accumulation of luteoviruses in co-infected plants. Ann. Appl. Biol. 115:71-78.

Barker, H., and Solomon, R. M. 1990. Evidence of simple genetic control in potato of ability to restrict Potato leaf roll virus concentration in leaves. Theor. Appl. Genet. 80:188-192.

Carrington, J. C., Kasschau, K. D., Mahajan, S. K., and Schaad, M. C. 1996. Cell-to-cell and long-distance transport of viruses in plants. Plant Cell 8:1669-1681.

Chay, C. A., Gunasinge, U. B., Dinesh Kumar, S. P., Miller, W. A., and Gray, S. M. 1996. Aphid transmission and systemic plant infection determinants of barley yellow dwarf luteovirus-PAV are contained in the coat protein readthrough domain and $17-\mathrm{kDa}$ protein, respectively. Virology 219:57-65.

Citovsky, V., and Zambryski, P. 1991. How do plant-virus nucleic-acids 
move through intercellular connections? Bioessays 13:373-379.

Citovsky, V., and Zambryski, P. 1993. Transport of nucleic acids through membrane channels-snaking through small holes. Annu. Rev. Microbiol. 47:167-197.

Commandeur, U., and Martin, R. 1993. Investigations into the molecular biology of potato leafroll luteovirus by means of agroinoculation. (Abstr.) Phytopathology 83:1426.

Derrick, P. M., and Barker, H. 1997. Short and long distance spread of potato leafroll luteovirus: Effects of host genes and transgenes conferring resistance to virus accumulation in potato. J. Gen. Virol. 78:243-251.

Derrick, P. M., and Nelson, R. S. 1999. Plasmodesmata and long distance virus movement. Pages 315-339 in: Plasmodesmata. Structure, Function, Role in Cell Communication. A. J. E. van Bel and W. J. P. van Kesteren, eds. Springer. Berlin.

Ding, X. S., Carter, S. A., and Nelson, R. S. 1998. Tobamovirus and potyvirus accumulation in minor veins of inoculated leaves from representatives of the Solanaceae and Fabaceae. Plant Physiol. 116:125-136.

Ding, X. S., Shintaku, M. H., Carter, S. A., and Nelson, R. S. 1996. Invasion of minor veins of tobacco leaves inoculated with tobacco mosaic virus mutants defective in phloem-dependent movement. Proc. Natl. Acad. Sci. U.S.A. 93:11155-11160.

Dufour, O., Palloix, A., Selassie, K. G., Pochard, E., and Marchoux, G. 1989. The distribution of Cucumber mosaic virus in resistant and susceptible plants of pepper. Can. J. Bot. 67:655-660.

Franco-Lara, L. F., McGeachy, D. K., Commandeur, U., Martin, R. R. Mayo, M. A., and Barker, H. 1999. Transformation of tobacco and potato with cDNA encoding the full-length genome of Potato leafroll virus: Evidence for a novel virus distribution and host effects on virus multiplication. J. Gen. Virol. 80:2813-2822.

Frisch, D. A., Harris-Haller, L. W., Yokubaitis, N. T., Thomas, T. L., Hardin, S. H., and Hall, T. C. 1995. Complete sequence of the binary vector Bin 19. Plant Mol. Biol. 27:405-409.

Gilbertson, R. L., and Lucas, W. J. 1996. How do viruses traffic on the "vascular highway"? Trends Plant Sci. 1:360-360.

Guerini, M. N., and Murphy, J. F. 1999. Resistance of Capsicum annuиm 'Avelar' to pepper mottle potyvirus and alleviation of this resistance by co-infection with cucumber mosaic cucumovirus are associated with virus movement. J. Gen. Virol. 80:2785-2792.

Kozak, M. 1989. The scanning model for translation-an update. J. Cell Biol. 108:229-241.

Lazarowitz, S. G., and Beachy, R. N. 1999. Viral movement proteins as probes for intracellular and intercellular trafficking in plants. Plant Cell 11:535-548.

Leiser, R. M., Ziegler-Graff, V., Reutenauer, A., Herrbach, E., Lemaire, O., Guilley, H., Richards, K., and Jonard, G. 1992. Agroinfection as an alternative to insects for infecting plants with beet western yellows luteovirus. Proc. Natl. Acad. Sci. U.S.A. 89:9136-9140.

Lucas, W. J., and Gilbertson, R. L. 1994. Plasmodesmata in relation to viral movement within leaf tissue. Annu. Rev. Phytopathol. 32:387-411.

Lucas, W. J., and Wolf, S. 1999. Connections between virus movement, macromolecular signaling and assimilate allocation. Curr. Opin. Plant
Biol. 2:192-197.

Mayo, M. A., and Ziegler-Graff, V. 1996. Molecular biology of luteoviruses. Adv. Virus Res. 46:413-460.

Nelson, R. S., and van Bel, A. J. E. 1998. The mystery of virus trafficking into, through and out of the vascular tissue. Prog. Bot. 59:476-533.

Nurkiyanova, K. M., Ryabov, E. V., Commandeur, U., Duncan, G. H., Canto, T., Gray, S. M., Mayo, M. A., and Taliansky, M. E. 2000. Tagging Potato leafroll virus with the jellyfish green fluorescent protein gene. J. Gen. Virol. 81:617-626.

Oparka, K. J., and Turgeon, R. 1999. Sieve elements and companion cells Traffic control centers of the phloem. Plant Cell 11:739-750.

Prüfer, D., Schmitz, J., Tacke, E., Kull, B., and Rohde, W. 1997. In vivo expression of a full-length cDNA copy of Potato leafroll virus (PLRV) in protoplasts and transgenic plants. Mol. Gen. Genet. 253:609-614.

Ryabov, E. V., Fraser, G., Mayo, M. A., Barker, H., and Taliansky, M 2001. Umbravirus gene expression helps Potato leafroll virus to invade mesophyll tissues and to be transmitted mechanically between plants. Virology 286:363-372.

Santa Cruz, S. 1999. Perspective: Phloem transport of viruses and macromolecules-What goes in must come out. Trends Microbiol. 7:237-241.

Schmitz, J., StussiGaraud, C., Tacke, E., Prüfer, D., Rohde, W., and Rohfritsch, O. 1997. In situ localization of the putative movement protein (pr17) from potato leafroll luteovirus (PLRV) in infected and transgenic potato plants. Virology 235:311-322

Séron, K., and Haenni, A.-L. 1996. Vascular movement of plant viruses Mol. Plant-Microbe Interact. 9:435-442.

Sokolova, M., Prüfer, D., Tacke, E., and Rohde, W. 1997. The potato leafroll virus $17 \mathrm{k}$ movement protein is phosphorylated by a membrane-associated protein kinase from potato with biochemical features of protein kinase C. FEBS (Fed. Eur. Biochem. Soc.) Lett. 400:201-205.

Tacke, E., Prüfer, D., Schmitz, J., and Rohde, W. 1991. The potato leafroll luteovirus $17 \mathrm{k}$ protein is a single-stranded nucleic acid binding protein. J. Gen. Virol. 72:2035-2038.

Tacke, E., Schmitz, J., Prüfer, D., and Rohde, W. 1993. Mutational analysis of the nucleic acid-binding $17 \mathrm{kDa}$ phosphoprotein of potato leafroll luteovirus identifies an amphipathic alpha-helix as the domain for protein-protein interactions. Virology 197:274-282.

Thompson, G. A., and Schulz, A. 1999. Macromolecular trafficking in the phloem. Trends Plant Sci. 4:354-360.

Tomenius, K., Clapham, D., and Meshi, T. 1987. Localization by immunogold cytochemistry of the virus-coded $30 \mathrm{k}$ protein in plasmodesmata of leaves infected with Tobacco mosaic virus. Virology 160:363-371.

Torrance, L. 1992. Analysis of epitopes on potato leafroll virus capsid protein. Virology 191:485-489.

Turgeon, R. 1989. The sink-source transition in leaves. Annu. Rev. Plant Physiol. Plant Mol. Biol. 40:119-138.

Ziegler-Graff, V., Brault, V., Mutterer, J. D., Simonis, M.-T., Herrbach, E., Guilley, H., Richards, K. E., and Jonard, G. 1996. The coat protein of beet western yellows luteovirus is essential for systemic infection but the viral gene products P29 and P19 are dispensable for systemic infection and aphid transmission. Mol. Plant-Microbe Interact. 9:501-510. 